\title{
CDISC SDTM Schizophrenia Findings About Test Name Terminology
}

National Cancer Institute

\section{Source}

National Cancer Institute. CDISC SDTM Schizophrenia Findings About Test Name

Terminology. NCl Thesaurus. Code C124303.

Terminology associated with the schizophrenia findings about test name codelist of the Clinical Data Interchange Standards Consortium (CDISC) Study Data Tabulation Model (SDTM). 